\title{
Wilkie's Syndrome in an Adolescent: A Rare Etiology of Upper Intestinal Obstruction
}

\author{
Roriz-Silva $\mathrm{R}^{*}$, Maranhão $\mathrm{T}^{2}$ and Schesquini $\mathrm{KRP}^{3}$ \\ ${ }^{1}$ Division of General Surgery, Hospital de Base of Porto Velho, Federal University of Rondônia (Unir), Brazil \\ ${ }^{2}$ Division of General Surgery, Hospital de Base of Porto Velho, State of Rondônia, Brazil \\ ${ }^{3}$ Department of Medicine, Division of Pediatrics, Federal University of Rondônia (Unir), Brazil
}

*Corresponding author: Roriz-Silva R, Adjunct Professor, Department of Medicine, Federal University of Rondônia, Division of General Surgery, Hospital de Base of Porto Velho City, Brazil, Tel: 55(69) 981190946, E-mail: roriz-silva@unir.br

Citation: Roriz-Silva R, Maranhão T, Schesquini KRP (2017) Wilkie’s Syndrome in an Adolescent: A Rare Etiology of Upper Intestinal Obstruction. J Case Rep Stud 5(2): 205. doi: 10.15744/2348-9820.5.205

Received Date: March 22, 2017 Accepted Date: April 26, 2017 Published Date: April 28, 2017

\begin{abstract}
Wilkie's Syndrome (WS) was described in 1927 and its physiopathology is related to the formation of an abnormal acute aortomesenteric angle measuring between $7^{\circ}$ and $22^{\circ}$. It leads to digestive symptoms due to external compression of mesentery artery against the third portion of duodenum. This is a case of WS in a young, tall and slim male patient. Three months before, he began postprandial vomiting, abdominal pain, hyporexia and weight loss. The diagnostis was made by an upper gastrointestinal series with barium contrast and confirmed by Laparotomy. Duodenojejunostomy is a well-known technique and it was successfully performed in this case.
\end{abstract}

Keywords: Wilke’s Syndrome; Superior Mesenteric Artery Syndrome; Mesenteric Duodenal Compression Syndrome; Duodenal Obstruction; Surgery; Duodenojejunostomy

List of Abbreviations: WS: Wilkie’s syndrome; CT: Computed tomography; UGS: Upper Gastrointestinal Series; BMI: Body Mass Index; SMAS-like: Superior Mesenteric Artery Syndrome-Like Syndrome

\section{Introduction}

Wilkie's syndrome or Superior Mesenteric Artery Syndrome is a rare condition of upper intestinal obstruction. In the general population, the incidence is from 0.013 to $0.3 \%$ [1]. This disorder is characterized by extrinsic compression of the third portion of the duodenum due to an abnormal acute angle between the aorta and the superior mesenteric artery, or due to presence of an overlapping of the ligament of Treitz in the retroperitoneum [1]. The syndrome has been known since 1842 and was first described by Carl Von Rokitansky [2]. In 1878, Willet reported a case of death secondary to what he named fatal vomiting [3]. In 1927, Doctor Wilkie described a series of 75 patients with the so-called "duodenal ileus", and 64 of them were submitted to duodenojejunostomy that confirmed the mechanism of extrinsic duodenal compression [4]. In most cases, the onset is insidious with postprandial nausea and vomiting, pain mainly in the epigastrium and weight loss [5]. As to diagnostic exams the gold standard examination is CT angiography and 3D-reconstruction but Upper gastrointestinal series (UGS) is a simple examination and can diagnose this syndrome as well [6]. The surgical treatment of WS should be performed after a conservative treatment that includes fluid and electrolyte replacement, hydration and appropriate nutritional support. The main surgical option is duodenojejunostomy [5,7]. The aim of this study is to report a rare case of upper bowel obstruction (Wilkie's Syndrome) in an adolescent and make important considerations about its pathophysiology, diagnosis and treatment.

\section{Case Report}

A male patient, 17-year of age, slim, height 1.8 meters ( $5 \mathrm{ft} 11 \mathrm{in}$ ), weight $54 \mathrm{Kg}$ (119 Ib), and BMI of 16.7. The patient presented with postprandial vomiting and abdominal pain, cramps in the mesogastrium which began three months previously and were concurrent with hyporexia and weight loss over $17 \mathrm{~kg}$ during that period. He was admitted to the Division of General Surgery of the Hospital de Base, in the city of Porto Velho, Brazil and physical examination showed malnutrition status with emaciation - grade 3 - according to World Health Organization. Laboratory tests revealed some alterations - low hemoglobin and albumin. An abdominal plain CT showed relative distension of stomach and first duodenal portion without evidence of neoplasm or other abdominal abnormalities. After hospital admission, an upper gastrointestinal series was performed and showed an area of stenosis in the third portion of the duodenum, and minimal amount of jejunal loops (Figure 1A and B). The patient was submitted to exploratory laparotomy after parenteral nutrition support for three weeks and a laterolateral duodenojejunostomy was performed 
on two plans, in the second portion of the duodenum (Figure 2A and B). He developed extensive pneumonia in postoperative period (fourth day) and ventilatory support in the intensive care unit for two weeks was required. Patient progressed satisfactorily, being discharged four weeks after the surgery. He was followed after the surgical procedure for 2 years with complete reversion of symptoms.
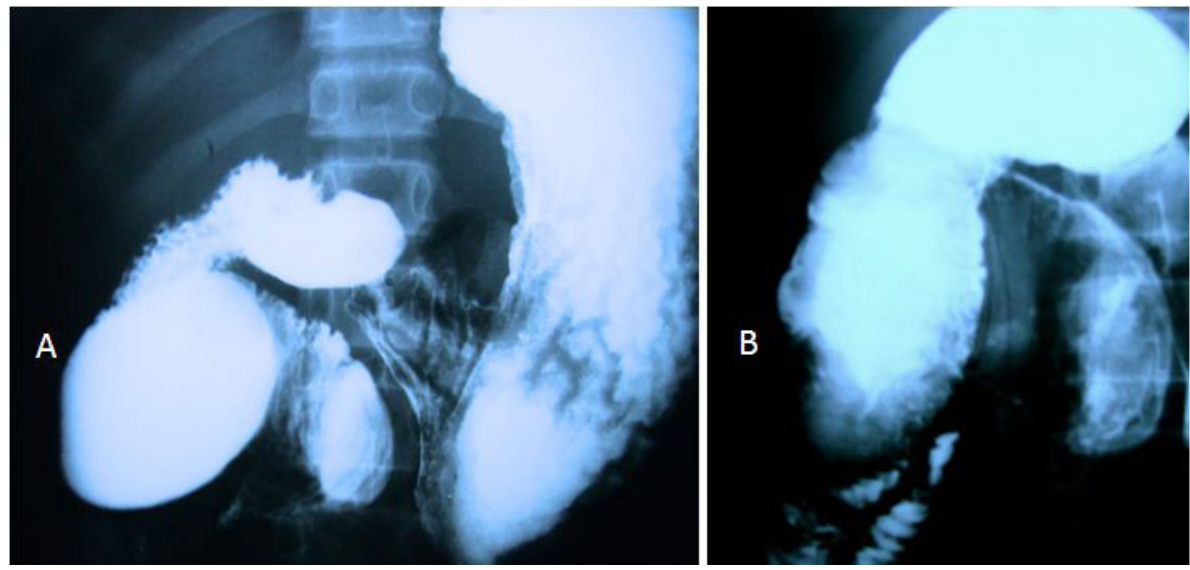

Figure 1: (A) Upper gastrointestinal series (UGS) with an intense gastric and duodenal distention. IT shows the piloric sphincter contraction during the exam; (B) Magnified image of UGS with duodenal distention first, second and part of third portion - and minimum passage of contrast to proximal jejunal loops

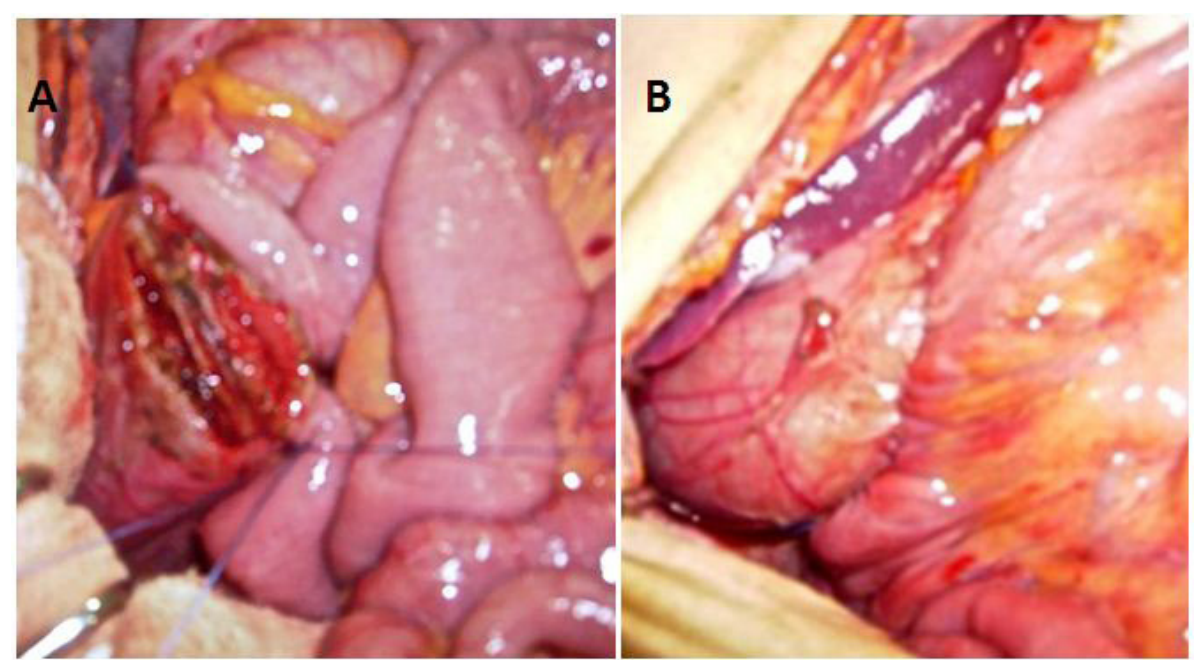

Figure 2: Duodenojejunal anastomosis made in two planes (A) Confection of first plan of anastomosis; (B) Final aspect of duodenojejunal anastomosis

\section{Discussion}

WS affects more individuals between 18-35 years with a slight predominance in females but other authors have published WS cases in the male population as well [5]. As to age group, there are reports in children and the elderly [8].

Anatomical characteristics of the region where the mesenteric vessels emerge are crucial to understand the pathogenesis of this syndrome. The origin of the mesenteric artery is in the right anterolateral wall of the abdominal aorta, anteriorly to the vertebra L1, passing anteriorly to the third portion of the duodenum. The duodenojejunal flexure is fixed in the parietal peritoneum, posterior to the ligament of Treitz, and originates from the right diaphragmatic pillar. This flexure involves the fourth duodenal portion and the duodenojejunal junction at L2 vertebra [9]. Normally an aortomesenteric angle ranges from $25^{\circ}$ to $60^{\circ}$ and is 10 to $28 \mathrm{~mm}$ distant from the duodenum [10]. The superior mesenteric artery syndrome results from the formation of an abnormal acute angle measuring between $7^{\circ}$ and $22^{\circ}$ and may have different causes, such as increased lumbar lordosis or use of orthotics for correcting posture [11]. Another important etiology of this syndrome is the loss of fat tissue close to the superior mesenteric artery and can to occur due to malnutrition, malignancy, diabetes mellitus, AIDS, heart diseases or neuropathy, abnormal insertion of the ligament of Treitz, abdominal aorta aneurism or tumor at the root of the mesenterium $[6,8,12]$. An infrequent cause associated to this syndrome is height growth in adolescence with no proportional weight gain [8]. This was probably the cause leading to SW in this reported case.

This syndrome does not always present with specific clinical characteristics, thus reducing initial clinical suspicion. The diagnosis may be delayed, leading to severe malnutrition and associated complications, such as infections [13]. In this case report, the patient developed severe pneumonia after the surgical procedure and one of the factors that interfered in that complication was the 
nutritional status [14]. Based on BMI, the patient was classified as having severe emaciation with a BMI of $16.7 \mathrm{~kg} / \mathrm{m}^{2}$ in addition to other findings of malnutrition.

The onset of symptoms may be acute with intense abdominal pain, persistent vomiting and bloating. In most cases, the onset is insidious with postprandial nausea and vomitus of varied intensity, pain - mainly in the epigastrium - and weight loss. The symptoms may be alleviated in left lateral decubitus and in fetal position [9].

Among the possible differential diagnoses, it is worth mentioning the so-called "superior mesenteric artery syndrome-like syndrome" (SMAS-like) with acute dilation of the duodenal arch of unknown etiology and secondary to some diseases, such as lupus, amyloidosis, dermatomyositis, scleroderma or myxedema. SMAS-like shows no change in the angle or in aortomesenteric distance, or even duodenal compression by the extrinsic mesenteric artery $[9,14]$.

Angiography is the main diagnostic examination and enables measuring the aortomesenteric angle, but the gold standard examination is CT angiography and 3D-reconstruction [6,10]. Several exams can be performed to rule out other causes of upper intestinal obstruction, including computerized tomography of the abdomen, upper oral contrast series and esophagogastroduedonoscopy $[6,9]$. In this case, abdominal CT did not suggest SMAS and UGS demonstrated duodenal obstruction. It could be because Barium was used in the second exam. It is a heavy material and it could produce increase of dilatation in the digestive tract before the point of obstruction better than other materials.

Surgical treatment of WS should be performed after a conservative treatment that includes fluid and electrolyte replacement, hydration and appropriate nutrition support [14]. Surgery is indicated in cases of failure of clinical management, weight loss with no chance of adequate nutrition recovery, and extensive duodenal dilation [8]. It is crucial to understand the historical sequence of surgical procedures for this syndrome since the first operation until now. The first surgical option was gastrojejunostomy described by Stavely in 1908 [15]. Duodenal mobilization with an ample section of the ligament of Treitz, was described by Strong in 1958 [16]; Massoud was the first surgeon to perform the Strong technique by videolaparoscopy in 1997 [17]. In the following year, Gersin and Heniford conducted the first videolaparoscopic gastrojejunostomy [18]. Gastrojejunostomy with anterior transposition of the third portion of the duodenum is indicated in cases with gastric dilation andor peptic ulcer that hinder the mobilization of the duodenal arch [19]. Another technique, proposed by Yang, consists of a circular duodenal drainage method with triple anastomosis: duodenojejunal, gastrojejunal and jejunojejunal. It is indicated for patients with gastric atony, duodenal dilation greater than 8 $\mathrm{cm} \mathrm{H}_{2} \mathrm{O}$ or when the intraluminal pressure is above $15 \mathrm{~cm} \mathrm{H}_{2} \mathrm{O}$ [20]. In this case report, laterolateral duodenojejunostomy was performed through laparotomy but a lot of cases are being reported by laparoscopic approach including robotic assistance as well $[5,21]$. Duodenojejunostomy represents the major surgical procedure, with approximately $80 \%$ resolution and it is easy to perform and enables appropriate inspection of the abdominal cavity.

After operative procedures, some complications can occur in patients with upper intestinal obstruction. One of them is pneumonia and it occurred in this reported case. Some reasons can be related with the pathophysiology of it - use of nasogastric tube, pulmonary micro aspiration, gastric colonization by pathogen bacteria and immunologic system mechanism alterations due to malnutrition [22]. In this case, the patient had severe pneumonia and ventilatory support was needed for ten days. The bacterial pathogen Enterococcus Spp was identified by bacteriological culture method. Fortunately the patient had an adequate therapy with antibiotics (Vancomycin) and progressed satisfactorily. His case has been followed for 2 years and he has remained free from symptoms.

\section{Conclusion}

Wilkie's syndrome or Superior Mesenteric Artery Syndrome should always be considered in the differential diagnosis of cases suggesting high intestinal obstruction including younger populations. Delayed diagnosis may lead to severe consequences for patients and duodenojejunostomy continues to be the main procedure for this syndrome even though there are several surgical options.

\section{Acknowledgement}

The authors declare there is no conflict of interest or grants our research and we obtained a signed informed consent from the patient and guardian. Author contribution was shared between Doctor Roriz-Silva, Doctor Maranhão and Doctor Schesquini.

\section{References}

1. Fraser JD, St. Peter SD, Hughes JH, Swain JM (2009) Laparoscopic Duodenojejunostomy for Superior Mesenteric Artery Syndrome. JSLS 13: 254-9.

2. Rokitansky C (1842) Handbuch der pathologischen anatomie ( $1^{\text {st }}$ Edn) Springer, Germany.

3. Willett A (1878) Fatal vomiting following application of the Plaster of Paris Bandage in case of spinal curvature. St Barth Hosp Rep 14: 333-5.

4. Wilkie DP (1927) Chronic duodenal ileus. Am J Med Sci 173: 643-9.

5. Chang J, Boules M, Rodriguez J, Walsh M, Rosenthal R, et al. (2017) Laparoscopic duodenojejunostomy for superior mesenteric artery syndrome: intermediate follow-up results and a review of the literature. Surg Endosc 31: 1180-5.

6. Biswas A, Babu AA, Neelakantan S, Sarkar PS (2016) Superior mesenteric artery syndrome: CT findings. BMJ Case Rep doi: 10.1136/bcr-215885.2016.

7. Ylinen P, Kinnunen J, Hockerstedt K (1989) Superior mesenteric artery syndrome. A follow-up study of 16 operated patients. J Clin Gastroenterol 11: 386-91. 
8. Lippl F, Hannig C, Weiss W, Allescher HD, Classen M, et al. (2002) Superior mesenteric artery syndrome: diagnosis and treatment from the gastroenterologist's view. J Gastroenterol 37: 640-3.

9. Gómez-Beltrán OD, Martínez AV, Pérez-Manrique MC, Rodríguez JS, Febres EL, et al. (2011) Superior mesenteric artery syndrome in a patient with Charcot Marie Tooth disease. World J Gastrointest Surg 12: 197-200.

10. Mansberger AR, Hearn JB, Byers RM, Fleisig N, Buxton RW (1968) Vascular compression of the duodenum. Emphasis on accurate diagnosis. Am J Surg 115: 89-96.

11. Daher YH, Lonstein JE, Winter RB, Bradford DS (1986) Spinal deformities in patients with Charcot-Marie-tooth disease. A review of 12 patients. Clin Orthop Relat Res 202: 219-22

12. Zorrón R, Milcent M, Contreras M, Lukashok H, Marques R, Filho DM (2003) Laparoscopic repair of Superior Mesenteric Artery Syndrome: Sutured Handsewn Duodenojejunostomy Technique. Rev bras videocir 3: 87-91.

13. Sinagra E, Montalbano LM, Linea C, Giunta M, Tesè L, et al. (2012) Delayed-Onset Superior Mesenteric Artery Syndrome Presenting as Oesophageal Peptic Stricture. Case Rep Gastroenterol 6: 94-102.

14. Woodruff BA, Duffield A (2002) Anthropometric assessment of nutritional status in adolescent populations in humanitarian emergencies. Eur J Clin Nutr 56: $1108-18$.

15. Staveley AL (1910) Chronic gastromesenteric ileus. Surg Gynecol Obstet 11: 288-91.

16. Strong EK (1958) Mechanics of aortomesenteric duodenal obstruction and direct surgical attack upon aetiology. Ann Surg 148: 725-30.

17. Massoud WZ (1995) Laparoscopic management of superior mesenteric artery syndrome. Int Surg 80: 322-7.

18. Gersin KS, Heniford BT (1998) Laparoscopic duodenojejunostomy for treatment of superior mesenteric artery syndrome. JSLS 2: 281-4.

19. Duvie SO (1988) Anterior transposition of the third part of the duodenum in the management of chronic duodenal compression by the superior mesenteric artery. Int Surg 73: 140-3.

20. Yang W-L, Zhang X-C (2008) Assessment of duodenal circular drainage in treatment of superior mesenteric artery syndrome. World J Gastroenterol 14: 303-6.

21. Ayloo SM, Masrur MA, Bianco FM, Giulianotti PC (2011) Robotic Roux-en-Y duodenojejunostomy for superior mesenteric artery syndrome: operative technique. J Laparoendosc Adv Surg Tech A 21: 841-4.

22. DiBardino DM, Wunderink RG (2015) Aspiration pneumonia: a review of modern trends. J Crit Care 30: 40-8.

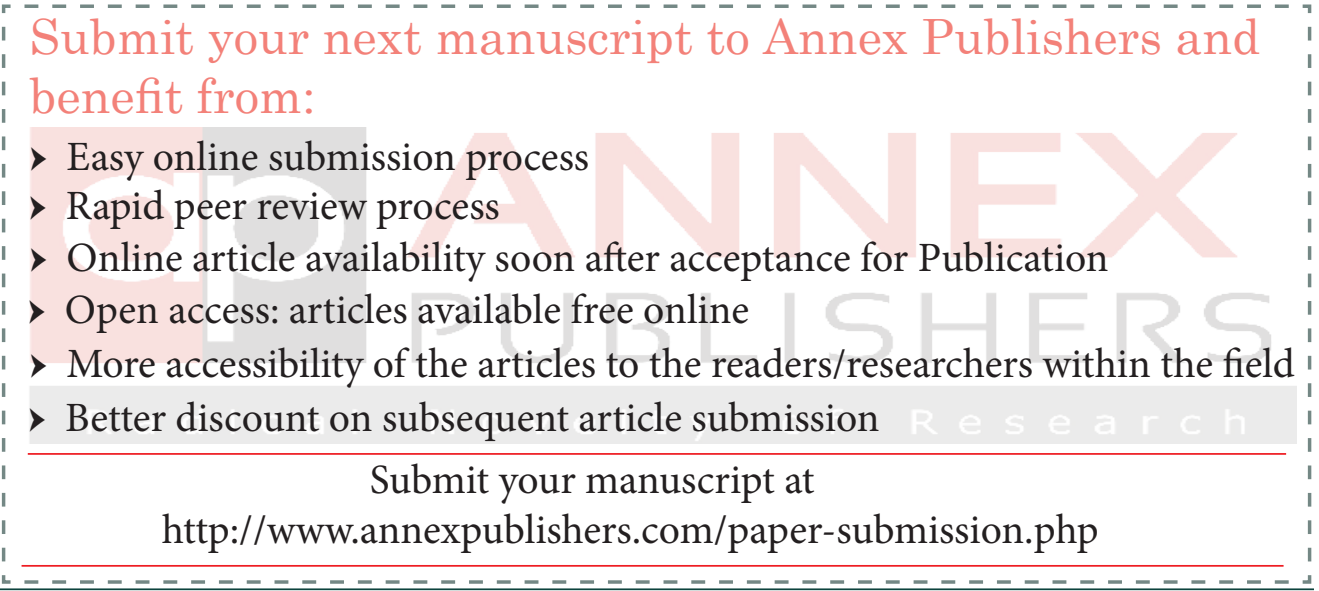

